\title{
Promoting Counseling Students' Advocacy Competencies through Service-Learning
}

\author{
Christine E. Murray and Amber L. Pope
}

The University of North Carolina at Greensboro

\section{P. Clay Rowell}

North Georgia College and State University

\begin{abstract}
This article describes an action research evaluation of a service-learning advocacy project implemented in doctoral-level and masters-level classes in a CACREP-accredited counseling program. The project involved students working together (a) to develop public policy guides related to the 2008 Presidential election and (b) to plan and implement an event designed to inform the public about policies relevant to sexuality, career issues, and mental health. The qualitative action research evaluation of the project focused on students' perceptions of the project throughout its implementation. The results indicate that the project holds value for student learning and service to the community, although students may vary in their perceptions of the project. The authors conclude with future directions for research and counselor education.
\end{abstract}

\section{Using Service-Learning to Promote Competence in Advocacy}

Advocacy has been described as "a professional imperative" (Myers, Sweeney, \& White, 2002) for the counseling profession. Within the counseling profession, advocacy is inclusive of both "social activism as well as the promotion of the profession" (Myers \& Sweeney, 2004, p. 466; see also Myers, Sweeney, \& White, 2002). Advocacy can be regarded as a form of social justice 
work that targets societal and institutional practices that create barriers for clients to achieve access to tools for self-development and challenges social oppressions and inequality (Goodman, Liang, Helms, Latta, Sparks, \& Weintraub, 2004; Kiselica \& Robinson, 2001). In 2003, the American Counseling Association (ACA) took a public stance to recognize the importance of advocacy in the profession by endorsing Advocacy Competencies for counseling professionals. Moreover, Counselors for Social Justice (CSJ), an ACA division, has put forward a position statement calling for the infusion of the Advocacy Competencies into counselor education programs as a means to promote social justice (CSJ, n.d.). The majority (79\%) of participants in a survey of leaders in the counseling profession indicated that they believed that counselor advocacy was most important "to the future of the counseling profession" (Myers \& Sweeney, 2004, p. 469). However, despite this growing interest in advocacy in the counseling profession, many counselors lack training in advocacy information and skills (Myers, Sweeney, \& White, 2002).

This article describes an action research evaluation of a service-learning advocacy project that was implemented in two counselor education courses-a masters-level Sexuality Counseling course and a doctoral level Career Counseling course-in a program accredited by the Council for Accreditation of Counseling and Related Educational Programs (CACREP). The purpose of this study was to identify the benefits of this project for students, the challenges students faced through the project, students' suggestions for improving similar projects in the future, and the value and usefulness of the service-learning advocacy project for student learning.

\section{Advocacy Competencies}

The ACA (2003) Competencies validate the importance of counselors developing understanding of the manner in which the larger context, such as economics and politics, impact the lives of clients. The Competencies indicate that advocacy may be an appropriate response for counselors if they become aware that these larger contextual issues have the potential to inhibit the positive growth of client populations, and can occur on a client, community or public arena level. Counselors therefore should develop competence in (a) empowering clients by helping them build advocacy skills, (b) negotiating relevant services to help clients access resources, (c) building collaborative relationships with relevant community agencies to address these challenges, (d) implementing systems-level advocacy initiatives, (e) communicating relevant information to the public, and ( $f$ ) engaging in social/political advocacy (ACA, 2003). Some specific behaviors related to the public arena level of these competencies, particularly the public information domain, include the abilities to "prepare written and multi-media materials that provide clear explanations of the role of specific environmental factors in human development, communicate information in ways that are ethical and appropriate for the target population, and disseminate information through a variety of media" (ACA, 2003, p. 3).

Researchers suggest, however, that counseling students have a low level of participation in advocacy activities (Nilsson \& Schmidt, 2005). One potential reason that counseling students and counseling professionals may be hesitant to become involved in advocacy efforts could relate to a lack of training. Nilsson and Schmidt (2005) stated, "Despite the call in the literature for counselors to become advocates for social justice issues, this value appears not to have filtered through graduate training programs to its trainees" (p. 277). Among the counseling profession's leaders surveyed by Myers and Sweeney (2004), a substantial proportion (41\%) of 
the participants indicated that a lack of training in advocacy created an obstacle to engaging in advocacy efforts. Myers and Sweeney (2004) concluded by stating, "Counselor educators have a vital role to play in advocacy efforts by emphasizing the importance of advocacy for the counseling profession and of preparing professional counselors with the necessary knowledge and skills to be effective advocates for their profession as well as for the clients they serve" ( $p$. 471).

Counselor educators must therefore consider the skills needed in order to train students to be effective advocates, as well as the instructional strategies that can be used for this training to be successful. We were unable to locate previous research testing strategies for training in advocacy skills. However, several skills have been noted as necessary for effective advocacy work, including an ability to inform policy makers about issues relevant to the counseling profession (Nilsson \& Schmidt, 2005); strong communication skills; the ability to plan and implement individual, group, and organizational interventions; skills in utilizing media and technology; and research and assessment skills (Kiselica \& Robinson, 2001). Nilsson and Schmidt (2005) also recommended that counseling students have opportunities to develop and practice advocacy skills, including organizing events and disseminating relevant information. Beyond advocacy skills, knowledge about relevant public policies, such as that which is available through the American Counseling Association's Public Policy web-site (http://www.counseling.org/PublicPolicy/) may be essential for conducting effective advocacy work.

In one of the first research studies of advocacy in the counseling profession, Eriksen (1999) conducted a qualitative study-including participant observation, informant interviews, and document analysis-to identify dimensions of advocacy among counseling professionals. Eriksen's interviews were conducted with individuals who had knowledge and experience related to counseling advocacy. Skills viewed as essential to successful advocacy include an emphasis on inclusiveness, taking an educational stance, strong communication skills, and matching the message to the needs and interests of the target population. Eriksen's (1999) research verified the importance in training counselors in advocacy skills in order for them to become effective advocates. Thus, the need exists for research examining strategies that counselor educators can use to promote these skills in their students.

\section{Advocacy as a Form of Social Justice Work}

Social justice work is regarded as efforts towards changing the societal and institutional context so that all individuals have equal access to basic rights, services, and goods that promote healthy human development (Goodman et al., 2004; Kiselica \& Robinson, 2001). Forms of social justice work include advocacy, prevention, social action research, program evaluation, and community interventions (Goodman et al., 2004; Kenny, Horne, Orpinas, \& Resse, 2009; Nilsson \& Schmidt, 2005). Other forms, particularly prevention, are of growing concern in the counseling field, although a full review of other forms is beyond the scope of this article (see Kenny et al., 2009, for a thorough review of prevention as social justice work). CSJ (n.d.) has recognized advocacy as an important form of social justice work, stating, "Social justice advocacy is a fundamental element of providing culturally sensitive and effective services to clients [and] therefore should be a core element in counselor education programs." Despite calls for integrating social justice advocacy into counseling and counseling psychology (CSJ, 
n.d.; Nilsson \& Schmidt, 2005), social justice work is still in the process of being defined by these fields into more concrete terms that counselors and counselor education programs can implement (Goodman et al., 2004). Only in the past decade and a half has the counseling profession has identified the skills (e.g., Eriksen, 1999) and competencies (e.g., ACA, 2003) needed for social justice advocacy.

Beyond the skills and competencies, Goodman et al. (2004) proposed a theoretical framework for social justice work based on the main tenets of feminist and multicultural counseling theories. From these theories, six principles to guide social justice work were identified: (a) ongoing self-examination, (b) sharing power, (c) giving voice, (d) consciousness raising, (e) focusing on strengths, and (f) leaving individuals with the tools for personal and social change (Goodman et al., 2004). Goodman et al.'s principles can help counselors translate some of the counseling skills they have developed to the competencies needed for social justice advocacy work.

Besides identifying the skills, competencies, and theoretical frameworks that guide social justice advocacy work, researchers also have examined the personal characteristics that were related to desired and actual involvement in advocacy among counseling graduate students using a social justice perspective (Nilsson \& Schmidt, 2005). These researchers surveyed 134 counseling graduate students (including counseling and counseling psychology students) at a university in the Midwestern United States. Overall, the researchers noted that there were low levels of social justice advocacy work among many of the participants. The researchers therefore recommended that counselor educators engage their students in discussions about politics and social issues, encourage involvement with culturally diverse groups, and teaching them advocacy skills. Nilsson and Schmidt (2005) concluded, "It is possible that graduate programs in counseling need to incorporate more explicit training in the execution of needed social justice practices" (p. 276). One way to teach students the skills needed to engage in advocacy as a form of social justice work is through the experiential approach of servicelearning.

\section{Experiential Approaches and Service-Learning in Counselor Education}

One approach for promoting advocacy skills within counseling graduate students can be found in experiential learning activities, and particularly service-learning. Counselor educators have consistently recognized the importance of experiential education in the training of counseling students (e.g., Pedersen, 2000). Moreover, counseling students have testified to the often powerful nature of experiential education in their learning process (e.g., Anderson \& Price, 2001). Experiential learning activities hold particular promise for the promotion of advocacy skills. First, counseling students may view experiential activities as more valuable than intellectual activities for their learning (Torres, Ottens, \& Johnson, 1997). Furthermore, experiential education can increase students' multicultural awareness (Villalba \& Redmond, 2008)—a key component of multicultural counseling competence (Sue, Arredondo, \& McDavis, 1992).

Service-learning is a form of experiential learning that integrates community service with classroom instruction (Murray, Lampinen, \& Kelly-Soderholm, 2006). Service-learning enhances the academic experience by allowing students to practically apply their awareness, knowledge, 
and skills in a manner that benefits the larger community. Additionally, it encourages students' commitment to civic responsibilities (Baggerly, 2006; Burnett, Long, \& Horne, 2005). Specifically, in counselor education programs, service-learning can help to expand students' focus beyond the individual relationship and promote their engagement in community activism as a means to help improve their clients' circumstances (Burnett, Hamel, \& Long, 2004). Murray et al. (2006) outline multiple benefits of service-learning, including enhancing students' knowledge of the course content and enthusiasm for the course, experiencing personal growth through increased self-awareness and self-efficacy, developing multicultural awareness and competencies, and positively affecting students' professional development through leadership opportunities and group involvement.

Service-learning is heavily incorporated into counselor education programs through internship and practicum experiences; however, there is minimal literature that explores the effectiveness of service-learning in relations to students' experiences outside of their internship and practicum components (Burnett et al., 2004). The few researchers who have explored the effectiveness of service-learning in counseling programs outside of internship and practicum experiences have found it to be a positive experience for students, particularly when the project is matched with students' developmental level of counselor training (Barbee, Scherer, \& Combs, 2003; Burnett et al., 2004).

\section{Project Description}

The project that was the focus of this study involved was described in one of the course's syllabus as "a whole-semester, entire-class project designed to help students build skills in advocacy, mental health education, and increasing the public's knowledge related to sexual health issues." This project intended to address students' development of the ACA Advocacy Competencies (2003) across the three levels of client, community, and the public arena. However, the nature of the project as a public awareness campaign dictated that students' advocacy competency development was concentrated in the public information domain of the public arena level of the ACA Competencies. The principles of social justice work, as identified by Goodman et al. (2004), that this project incorporated were giving voice and leaving clients with the tools for social change.

Students in three courses in a CACREP-accredited program were enrolled in the service-learning advocacy project during the Fall 2008 semester. The involved courses included (a) a sexuality counseling course, with four students enrolled, all of whom were advanced masters-level students enrolled in their final semester of study in the program's couple and family counseling track; (b) an advanced career theories and counseling course, which was comprised of ten firstyear counselor education doctoral students; and (c) a professional orientation course for firstyear masters students, with an enrollment of 31 students. These courses were selected for inclusion in the service-learning project based on the instructors' interest in including the project in their courses, the relevance of the project to the content of these courses, and because these courses included students at different stages in the counselor education program, thereby increasing the number of students able to participate in the project. Only the sexuality counseling and advanced career course students were included in the action research evaluation, however, because the students in the other class were given options by the instructor as to their level of involvement in the project. Therefore, the remainder of this article 
will focus on the project as it occurred within the sexuality counseling and advanced career counseling courses. There were some similarities and some differences in the manner in which the project was used in these two classes, and these will be noted in the remaining description of the project.

Prior to the semester in which the current project occurred, the first author, who is the instructor of the sexuality counseling course, had implemented similar public awareness campaign projects during two previous semesters. During those semesters, the students were given the freedom to select the topic, content, and format of their service-learning advocacy project, as long as it related directly to sexual health issues. These projects resulted in the creation and promotion of resources related to a comprehensive view of sexuality in couple relationships (during the first semester of implementation; http://www.uncg.edu/ced/bbandb/) and sexual wellness (during the second semester of implementation; http://www.uncg.edu/ced/swbk.html). Anecdotally, the response to these projects among the students was positive, and several indicated to the instructor that they enjoyed the opportunity to participate in an assignment that had an impact beyond the classroom. However, some previous students suggested that the project might be improved if the students were provided with a more direct focus for the assignment during subsequent semesters.

Thus, in planning for the Fall 2008 semester, the first author contacted the enrolled students prior to the start of the semester to offer them possible areas of focus for their service-learning advocacy project in the upcoming semester. Simultaneously, the first author and the third author, who was the instructor for the advanced career counseling course, began conversations about possible service-learning options for the career counseling course. The idea of an election-focused service-learning advocacy project grew out of these conversations, as the first author was familiar with another project that had been done at another university during the previous Presidential election year. This project was then presented to the sexuality counseling students as one option for the project, which the students ultimately chose for their assignment. The advanced career counseling course instructor decided to include the project in that class, and, upon learning of the project, the professional orientation course instructor also decided to include it as an option for those students as well.

Therefore, the service-learning advocacy project done by the sexuality counseling and advanced career counseling courses was related to the 2008 Presidential election. There were two components to this project, which the students titled, "Your Sex Life, Your Career, Your Mental Health ... Your Vote!" First, the students in each class worked together to develop policy guide books regarding the Presidential and/or Vice Presidential candidates' positions, voting records, and proposals about issues related to the topics of each class (e.g., sexuality, career development, and mental health). The sexuality counseling class students included both the Presidential and Vice Presidential candidates in their guide book, and the advanced career counseling students included only the Presidential candidates. These guidebooks were made available electronically through the project web-site (http://www.uncg.edu/ced/vote.html) and were intended to be a source of objective information about the candidates' stances on the covered issues.

Second, the students were required to plan and carry out an event to inform a target audience about the information gathered through the process of creating the policy guide books. The 
sexuality counseling class students took the lead in planning and preparing this event because the project was a larger component of that class as compared to the other classes. However, students in all three involved classes participated in this aspect of the project on the day of the event. The students determined that their target audience would be the campus community, and they planned a day-long, interactive exhibit that took place in the university's student union in a high-traffic area near the university bookstore and a large food court.

In previous semesters, the first author had allotted approximately 50 minutes of class time every week throughout the entire semester to the service-learning advocacy project. However, because the election occurred midway through the semester, the course schedule was adjusted accordingly, with additional class time being allotted in the beginning of the semester and the project being completed once the election was over. Therefore, although a similar amount of time was allocated to this project as compared to previous semesters, the distribution of this time across the semester was different with this project. Upon completion of the project, time was allotted during one session of each class for final processing and reflection upon the project, as is typical of service-learning methodologies (Eyler, 2002).

\section{Evaluation Methodology}

The present study incorporated a fusion of action research and consensual qualitative research methodologies to examine the process and impact of conducting the service-learning advocacy project in the two designated counselor education courses. Action research is used widely in the study of various educational methodologies. Action research involves "trying out ideas in practice as a means of increasing knowledge about or improving curriculum, teaching, and learning" (Ferrance, 2000, p. 26). Consensual qualitative research (CQR: Hill, Thompson, \& Williams, 1997) emphasizes consensus among judges to qualitative data in an exploratory, discovery-oriented process. The evaluation of the current project followed the five phases of action research: (a) problem identification, (b) data collection, (c) data interpretation, (d) action based on the data, and (e) reflection (Ferrance, 2000). For parts b and c above, we used CQR procedures for data collection and interpretation.

The aim of the study was to determine the project's impact on students' learning and to identify potential revisions to the project in future implementations of it in this and other counselor education programs. The corresponding research questions for this study were: (a) What benefits do students believe that the service-learning advocacy project holds for the development of their knowledge and skills related to their counselor education courses?; (b) What challenges do students face through their participation in the service-learning advocacy project, and how do they address these challenges?; (c) What suggestions do students have for improving the service-learning advocacy project in the future?; and (d) To what extent do students believe that the service-learning advocacy project was a useful and valuable assignment?

Data collection occurred in the following manner. Students had the option of participating in the action research study, and those who were interested in participating signed an informed consent document at the beginning of the semester (note that the informed consent documents were signed while the instructors were outside of the classroom). Data collection was ongoing throughout the duration of the project. In biweekly intervals (i.e., five times), the second author 
(who was the graduate assistant for the course) sent an e-mail to all students who agreed to participate in the action research project. This e-mail included four open-ended questions that correspond to the study's research questions as described above. Participants were asked to provide honest, detailed responses via an e-mail reply to the second author. The second author then compiled the responses into a database and removed any identifying information about the students. During the final data collection period (i.e., at the end of the project), an additional question was asked: What is your overall reaction to the service-learning advocacy project and its usefulness in this course? The data were coded to allow for the tracking of participants' responses over time at the individual level.

Attention was paid to the ethical considerations involved in this study. The major ethical issue related to this project stems from the fact that two of the researchers were also the course instructors. This arrangement is typical of action research, which has been used historically by educators seeking to improve their instructional methods (Ferrance, 2000). Nevertheless, it creates a dual relationship (i.e., instructor/student and researcher/participant) that warranted safeguards for students. First, this study was approved by the Institutional Review Board. Second, although students were required to participate in the project in order to pass the course, students were not required to participate in the study, and their decision whether or not to participate had no bearing on their grade for the course (ACA, 2005, standard G.2.c). Third, as an additional protection for students' confidentiality, the instructors did not have access to any of the raw data that contained identifying information about the students.

Data analyses and interpretation were ongoing throughout the semester, and CQR procedures were used to identify themes in student responses within each of the research questions and corresponding questions asked of students. According to Hill et al. (2005), the first step in CQR data analysis involves developing an initial list of codes to explain the data. The first author developed this list based on the interview questions and the literature. In the current study, the researchers independently coded the compiled student feedback based on this initial list. If any data did not seem to fit any initial code, the researcher created a new code.

The next step in CQR is for the researchers to meet and come to consensus on a final code list. The researchers once again independently coded the data based on the modified code list. This process of independently coding the data and then meeting to reach consensus occurred throughout the semester as new data was collected. The notes from these meetings became part of the data considered in the data analyses and interpretation. At the end of the semester, an emergent coding strategy was used to identify the themes in participants' responses to each of the questions, and the original data were subsequently coded according to the final coding schema. During the consensus meetings, when complete consensus was not achieved based on the researchers' original assigned codes for particular statements, the researchers discussed the statements in question and came to a consensus decision regarding the code to be applied to those statements. Inter-rater agreement was high, with an overall percentage agreement of $89.9 \%$, and 116 of 158 statements (73.4\%) demonstrating initial consensus among all three researchers.

Student participants were informed at the start of the semester that the emergent themes may reveal actions that can be taken during the semester to improve the project. These needs were discussed in the ongoing meetings between the research team, and they were subsequently 
addressed and monitored among the students. The nature of the needed actions related primarily to the explanation and structure of the project.

\section{Results}

All ten students enrolled in the career counseling course provided responses to at least one round of data collection. The numbers of career counseling students participating in each round of data collection were as follows: Round One (seven students); Round Two (three students); Round Three (five students); Round Four (three students); and Round Five (five students). Of the four students enrolled in the sexuality counseling course, three students responded to at least one round of data collection. The numbers of sexuality counseling students participating in each round of data collection were as follows: Round One (three students); Round Two (three students); Round Three (three students); Round Four (two students); and Round Five (three students). Due to the small class size and in an effort to further protect participant confidentiality, the demographic characteristics of participants were not assessed. However, the instructors report that the career counseling class was comprised of six females and four males, and the sexuality counseling course was comprised of four females.

In this section, we describe the themes that emerged within each question asked of students throughout the semester about the service-learning advocacy project. We present the description of each theme, along with illustrative quotations representing each theme.

\section{Benefits of the Service-Learning Advocacy Project}

Context and application. A number of students indicated that the project helped them to connect course material to the "real world" and to the larger social context. For example, one student stated, "I think that this project helps me to see these issues on a national and even global scale. It helps me to look at things from a broader perspective."

Policy knowledge and awareness. Several students also reported that the project helped them increase their personal understanding of public policy and politics. According to one student in the sexuality counseling class, "The campaign project has been a great eye opener to how the candidates view issues with women as well as with sexuality."

Advocacy skills, competence, and value. Several benefits were mentioned related to the project helping students develop an increased understanding of advocacy in the counseling profession. Some students indicated that they developed skills to conduct advocacy work through the project. One career counseling student said, "I think we will benefit in the areas of presentation skills and advocacy skills." Other students indicated that the developed advocacy competence and self-efficacy (i.e., confidence in their ability to do engage in advocacy, promotion, and service skills) through the project. As one career counseling student said, "It will encourage my confidence also in advocating for my profession and clients." Students also noted that they developed a greater appreciation for the value of advocacy for the counseling profession, as illustrated in the following statement by a sexuality counseling class student: "it has helped me to see the issues that we focus on more broadly. Also, that we need to be advocates as counselors and get involved with politics to try to create positive change." 
Promoting class dialogue. Another benefit of the project mentioned by students was that it prompted relevant class discussions. A career counseling student said, "I feel that this campaign has allowed us to have more meaningful conversations about how politics influences careers and career counseling."

Uncertain or minimal benefits. Despite the benefits mentioned above, five students reported that they were not sure if they gained any benefits from their participation in the servicelearning advocacy project related to their development of knowledge and skills connected to the content of the course. It is important to note that these statements were made only by students in the career counseling class, which the researchers believe may be related to concerns expressed in latter responses regarding the developmental level of the assignment, as will be addressed later in this section and the Discussion. One of these students said at the end of the semester, "It made me stop to focus on the significance of career issues and politics. But overall it did little for the development of my knowledge and skills related to the course."

\section{Challenges Students Faced through Participating in the Service-Learning Advocacy Project}

Organizational challenges. Many challenges faced by students through this project related to organizational issues and completing the project successfully. One specific organizational challenge involved time-related challenges. As one career counseling student said at the end of the semester, "The time to prepare for the project was the most challenging...We were given a small amount of time in class to address the project." Another organization-related challenge was related to information, in that some students indicated that they faced challenges related to finding credible information about candidate's positions, as well deciding about what information they would use for the project. According to a career counseling student, "Challenges so far have simply been about sifting through the myriad sources of information and choosing what is important." Other organization-related challenges related to communication and coordination, in that some students reported that they were challenged by the extent to which the project required communication and coordination with the other involved classes, each other within the classes, and the professors. In describing the strategies used to manage this challenge, a sexuality counseling student reported that "by keeping in good communication and delegating tasks to everyone, we were able to get everything done w/o too much stress on one individual." Other general organizational issues were mentioned by students, such as the following statement made by a sexuality counseling student: "I think the only challenge I have faced with the campaign project is feeling like everything is covered and taken care of because we created the structure of the project while generating the content for it."

Meaning and motivation. Two students in the career counseling class reported that they faced challenges related to finding meaning in the project, feeling connected personally to the project, and wanting to engage in the required work. As one of these students said at the first round of data collection, "I have faced the challenge of getting started, and have essentially accepted the fact that I have a few weeks yet to accomplish this." Later in the semester, this same student said at the fourth round of data collection, "I have addressed the challenge of choosing to care about his project. I have addressed this challenge by remembering the project's influence on my grade and the usefulness of the candidate info to the public." 
Feeling overwhelmed. Another challenge mentioned by two students in the sexuality counseling course related feeling overwhelmed by the demands of the project. According to one student, "It was...overwhelming at times to have to organize all the classes and make sure the event ran smoothly."

\section{Students' Suggestions for Improving the Service-Learning Advocacy Project}

Although some students reported that they did not have suggestions, others provided practical suggestions for improving the project in the future. Some suggestions were specific to the chosen activities of the presidential election-themed project, and these will not be discussed because they will be less useful to counselor educators engaging in other specific activities.

Modify the scope of the project. Some students suggested that the project would be improved if the scope of the project and the level of focus given to the project in class were modified. Some students indicated that the project should be expanded in timing and/or scope in order to have a greater impact. As a career counseling student said, "I actually think we could have done more. One brief...position paper with a 10 minute presentation to the class. We could have vetted some of the issues, discussed, and decided which ones to focus for the project." Two career counseling students reported that they would have liked other course expectations and the course workload to have been reduced in order to provide more time in class for the project. One of these students requested the following: "Please take away at least one other reading and presenting responsibility if assigning this type of project in the future." Another scope-related theme was to have more continuation across classes, such as having similar projects in other classes and having this type of advocacy project become more integrated into departmental learning objectives. A sexuality counseling student said, "I think that we should continue advocacy and awareness campaigns as a department."

Developmental level, course tie-in, and engagement. One of the doctoral students suggested that this assignment may have been more appropriate for students at the master's level. This student suggested the following: "Keep this project at a Master's level. It is more developmentally appropriate to assist students in thinking things through in a more dialectical manner. At the doctoral level - we seemed bored with this!" Two possible factors contributing to this suggestion relate to students' perspectives about (a) the level of tie-in and connection of the project into the class and the class content and (b) the extent to which students had an active, engaged role in the project, as well as a say in the direction and focus of the project. Regarding the former, a career counseling class student said, "I suggest finding ways to make the project feel more connected for the class. The career component of our project did not feel as salient to the election as I had hoped." With respect to the latter factor, a different career counseling student suggested that the "project would be more beneficial to the students if...the students had a little more say in the direction of the project in terms of content or approach."

Organization and communication. In light of the organizational challenges faced by some students through this project described above, some suggestions for improving the project related to organization and communication and collaboration. A sexuality counseling student said, "The only suggestion I have for a possible future version of this project is to have an outline of all the duties at the onset to provide more organization for the project." As another example, a career counseling student suggested mid-way through the semester: "I think having 
more collaboration with the other classes would be helpful so we were not re-doing what they are already doing."

\section{Students' Perceptions of the Use and Value of the Service-Learning Advocacy Project}

Usefulness for learning and service. True to the nature of service-learning activities, several students noted the value of the project as a learning tool, and that they believed the project resulted in a valuable service for the target community (i.e., college students). According to one sexuality counseling student, "We are learning more about the course material and about our government. This is good-as counselors, we need to be aware of the government that we are working in and knowledgeable about changes in society." As another sexuality counseling student said, "It was valuable for us, who planned it and also to the public...We all learned from this."

Usefulness for developing skills. Another area in which the project was viewed as being useful and valuable was found in the development of skills, such as advocacy and event planning skills. A sexuality counseling student said, "I think it was again helpful in understanding all the work that gets put into events such as this."

Usefulness and relevance. Some students commented that the project was particularly useful given its relevance for the timing of the Presidential election. As one career counseling student said, "I think it was a valuable assignment. I think there was energy behind it because it was an historic election year."

\section{Additional General Impressions}

As part of the final round of data collection, students were also asked to describe their overall impressions of the project. Students' responses revealed the following themes.

Class ties and application. This theme reflected students' ideas about the project needing to be tied more closely to the class content. As one career counseling student said, "I just wish there had been more discussion about what each of us found and thought was significant."

Creative thinking prompted by the project. These statements reflected students' perspectives that the project was creative and prompted them to thinking in more abstract ways. According to a career counseling student, "Overall, it got the class thinking in a different way." Another student in that class said, "I thought it was a creative, innovative and relevant approach for a practicum project."

Fun aspects of the project. Comments within this theme reflected students' appreciation for the project being a fun, intriguing, and enjoyable experience. A sexuality counseling student said, "I really liked the project and how it turned out. It was fun and the students on campus really seemed to like the event and the information they received."

The broader application of the project. The broader application of this project was noted with regards to its impact and the opportunity it provided to generalize counseling skills to 
community-level projects. One sexuality counseling student said, "I feel like it added another real world application of the course material (besides counseling implications)."

Skills developed through the project. The project was described as providing an opportunity for students to develop and become comfortable with new skills, as illustrated by the following comment from a sexuality counseling class student: "I think that it has gotten us more comfortable with awareness promotions, etc."

The appropriate developmental level of the project. Again, the issue of whether this project is appropriate at the doctoral level was raised in response to this question. As one career counseling student said, "At the master's level the assignment provided the students an opportunity to begin thinking more dialectically in relation to...issues that they may not have considered. At the doctoral level we were all very aware of the issues."

Overall positive experiences with the project. Some students noted that the project was a generally valuable and positive experience for them. As one sexuality counseling student said, "I liked this project; I felt that it was a project with impact and importance (which is nice)." Another student in the career counseling class said, "Short form: loved it!"

\section{Discussion}

\section{Limitations}

The findings of this study must be considered within the context of its limitations. First, although typical of action research, it is important to note that two members of the research team were also the course instructors. As such, the instructors' biases and own reactions to the service-learning advocacy project could have influenced their interpretations of the study data provided by students. Likewise, although steps were taken to ensure that student participants' responses to the questionnaires were not linked to their identities when presented to their course instructors, it is possible that the participants' openness to responding to the questionnaires was influenced by potential confidentiality concerns. Another limitation of this study is that it was conducted at one university, and the sizes of the classes from which the participants were drawn were small. Furthermore, this study utilized qualitative methodology only, and future research could benefit from adding quantitative measures to assess various student learning outcomes related to similar projects. Additional procedures for adding more rigorous qualitative research strategies (e.g., the researchers maintaining reflexive journals and triangulating themes with participants) may be useful for improving future similar studies. Finally, students' responses were not able to be considered within the context of their demographic and professional background characteristics (e.g., gender, age, political ideologies, and, for doctoral students, extent of previous professional experience). Finally, although social justice work was discussed in the form of advocacy with the students throughout this project, the connection between advocacy and social justice work was not made explicit to the students. Thus, a limitation of this study is that the researchers did not use the social justice framework to inform and guide the discussions of counseling advocacy and service-learning, which may have been useful in enhance students' understanding of the importance of advocacy and given them a structure in which to view the development of their skills throughout this project. 


\section{General Conclusions and Implications for Practice and Research}

Overall, the service-learning advocacy project appears to hold value for the promotion of advocacy skills and competence among counseling graduate students. Students' responses suggest that such a project holds value as both a learning experience for students and a service to the community. In particular, participating in a class-based advocacy project can help students develop advocacy competencies across the client, community, and public arena levels related to identifying the social, cultural, environmental, institutional, and political factors that affect clients' lives (ACA, 2003). This project promoted students' development of these competencies through helping them apply course material to the larger social context and facilitating their awareness of relevant public and political policies that impact clients and communities. Further, the students, particularly those in the master's level class, reported developing competencies in the public information domain of the public arena level through the preparation, communication, and dissemination of information relating to the political candidates' views on relevant sexuality, career, and mental health policies. Students reported feeling more confident in their abilities to create a public awareness campaign, and developing an understanding of the work and energy needed to successfully enact such distribution of information.

Furthermore, the project may provide students with an enjoyable experience that prompts them to engage in creative thinking about their studies. However, it is important to note that students differ in their receptiveness to this type of project. Students' reactions to a service-learning advocacy project that may be influenced by the extent to which they face and are able to manage the challenges the project presents, such as becoming organized to complete the project and finding meaning and motivation to engage in the project. Finally, although the social justice framework developed by Goodman et al. (2004) was not presented to the students throughout this project, the students identified the public awareness campaign as promoting individuals' voices by underscoring the importance of voting in the 2008 election and providing individuals with the tools, in this case the distributed information about the candidates' political platforms, to make informed decisions that will influence social change.

The findings of this study suggest that counselor educators who plan to incorporate similar service-learning advocacy projects into their courses should consider carefully (a) the appropriate developmental level of the project for the students involved, (b) strategies to present the project to students that will promote their engagement in the assignment, (c) provide a more specific theoretical framework in which to guide students' development of their advocacy skills, and (d) various organizational considerations that are required for a project to be implemented successfully.

Because the project was implemented in both a doctoral-level and an advanced masters-level course, this study offers some insight into the different needs of students at each level. It is important to note again that the two courses had differing levels of involvement in this project, so the experiences of the students in each class cannot be considered as equal. As noted earlier, the students in the masters-level sexuality counseling course played a more active role in developing, managing, and coordinating this project. Prior to the start of the semester in which the project was implemented, it was arranged by the instructors that the students in the sexuality counseling course would take primary responsibility for determining the direction and 
format of the project. Students in the career counseling course therefore followed the directions of the sexuality counseling students with regard to what they would do at the project-related event and the information they would include in the policy guidebook they created. These arrangements were made by the instructors with regard to other class expectations and objectives.

However, some doctoral students' comments through this study suggested that taking the role of following the directions of the masters students may have resulted in the doctoral students becoming less engaged in the project. This is not to say that the masters-level students were not capable of coordinating the project; it is evident from their responses to this study that they were quite capable and that they benefited educationally and professionally from doing so. Rather, counselor educators who implement similar service-learning advocacy project in doctoral-level courses may want to ensure that these students have greater opportunities to control the direction of the project, particularly with regard to planning and creative thinking. If the project described in this article were to be implemented again with both levels of students participating, strategies for increasing the meaning of the project for the doctoral students could have included having each course be responsible for coordinating one aspect of the project (i.e., the guidebook or the project-related event) or doing two separate projects with a similar theme, in which each class was fully responsible for planning and carrying out one project.

Counselor educators who implement service-learning advocacy projects in the future also are encouraged to present the project to students in a manner that will promote and maintain their engagement in the assignment. The results of this study indicate that one of the most important strategies for doing this involves making clear connections between the project and the content and objectives of the course. Students appeared to struggle with this project when they viewed it as having limited direct relevance to their coursework. On the other hand, students appreciated when the project provided them with opportunities to make connections between their course materials and the broader social context, such as public policies and needs within the larger community. Based on the findings of this study, we recommend that counselor educators using similar projects in the future utilize the following strategies: (a) When first presenting the project to students, describe a clear rationale for its relevance and importance to the topic of study; (b) Ensure that the course is structured to allow students to have adequate time and energy (both within and outside of class) to devote to the project; (c) Consider developing multi-semester projects so that the learning is not limited to a single semester; (d) Create opportunities during class discussions to relate material covered in class (e.g., readings, lectures) to the skills and knowledge being developed through the servicelearning advocacy project; (e) Throughout the duration of the project, allot time for student reflection on their direct learning experiences through the project (Eyler, 2002); and (f) If it becomes apparent that students' motivation and engagement for the project is lacking while the project is being implemented, address these concerns through frank course discussions with students and work with students to develop strategies for enhancing their engagement in the project.

Counselor educators planning service-learning advocacy projects also should enter into these projects with a full acknowledgement of the various organizational considerations for such projects to be implemented successfully. The time and energy demands of service-learning 
projects for faculty members have been noted previously (Stadtlander, 2002). Thus, faculty members should make efforts in advance to help ensure an organized, well-planned project. These efforts can begin with a detailed description of the assignment in the course syllabus. Descriptions of project-specific behaviors expected of students can also be provided to support students in their work. Effective communication appears to be an essential element of a successful project, among classmates, between students and professors, and, if applicable, between the classes involved in multi-class projects. Assigning a liaison between classes in multi-class projects can help to facilitate this latter form of communication and collaboration, which was the case with the project described in this article. As one student said, "We have a liaison between our class and the others which has helped." Depending on the nature of the assigned project, other organizational issues that may need to be considered include developing a time-line, creating a budget, and providing students with access to informational resources related to the project.

The study described in this article can serve as a foundation for future research relating to the effectiveness of service-learning projects in counselor education courses, as well as the development of advocacy skills among counseling graduate students. Future studies should be conducted to evaluate the impact of service-learning activities on such student learning outcomes as course grades, knowledge of counseling advocacy competencies, and long-term engagement in advocacy- and service-related activities within the counseling profession. Specifically incorporating a social justice theoretical framework, such as the one created by Goodman et al. (2004), may provide students with a structure to comprehend their advocacy skill development and would serve as an efficient guide for future research. A combination of qualitative and quantitative methodologies can provide counselor educators with different types of understanding of how best to include these projects in their courses.

Beyond assessing the impact of these projects for student outcomes, future research is needed to determine the impact that service-learning advocacy projects have upon the broader systems they are intended to influence. This research may be focused on the basic impact of these projects (e.g., How many people read materials developed by students?; How many people attended events hosted by students?), as well as on the extent to which students' efforts result in desired behavioral and/or attitudinal changes (e.g., To what did members of the target audience develop increased knowledge about public policy through the project materials?; How likely were members of the target audience likely to change their decisions about voting based on the information they learned through the project materials and activities?). Students may be able to be engaged in these evaluation processes, further adding to their opportunities to develop knowledge and skills through these projects.

Finally, as the counseling profession continues to move toward greater recognition of the value of advocacy as a form of social justice work for the profession (ACA, 2003; Myers \& Sweeney, 2004; Myers, Sweeney, \& White, 2002), research can be conducted to identify the effectiveness of the skills and knowledge foundations that promote professional advocacy. Equipped with this information, the profession can move forward in developing and refining instructional methods for training students to develop competence in advocacy for the profession and for promoting the welfare of clients and society. 
Contact information/Correspondence:

Christine E. Murray

224A Curry Building; Greensboro, NC 27412

Email: cemurray@uncg.edu

Christine E. Murray, Ph.D., LPC, LMFT, Assistant Professor; Amber L. Pope, M.S., LPC, Doctoral Student; The University of North Carolina at Greensboro; and P. Clay Rowell, Ph.D., LPC, Assistant Professor; Community Counseling Program; North Georgia College and State University. This study was supported by a research grant from the Southern Association for Counselor Education and Supervision.

\section{References}

Alderson, K. G. (2004). A different kind of outing: Training counselors to work with sexual minority clients. Canadian Journal of Counseling, 38, 193-210.

Anderson, R. D., \& Price, G. E. (2001). Experiential groups in counselor education: Student attitudes and instructor participation. Counselor Education \& Supervision, 41, 111-119.

American Counseling Association (ACA; 2003). Advocacy Competencies. Alexandria, VA: Author. Retrieved October 29, 2008, from http://www.counseling.org/Publications.

American Counseling Association (ACA; 2005). ACA Code of Ethics. Alexandria, VA: Author. Retrieved February 20, 2008, from http://www.counseling.org/Resources/CodeOfEthics/TP/Home/CT2.aspx.

Baber, K. M., \& Murray, C. L. (2001). A postmodern feminist approach to teaching human sexuality. Family Relations, 50, 23-33.

Baggerly, J. (2006). Service-learning with children affected by poverty: Facilitating multicultural competence in counseling education students. Journal of Multicultural Counseling \& Development, 34, 244-255.

Barbee, P. W., Scherer, D., \& Combs, D. C. (2003). Prepracticum service-learning: Examining the relationship with counselor self-efficacy and anxiety. Counselor Education \& Supervision, 43, 108-119.

Burnett, J. A., Hamel, D., \& Long, L. L. (2004). Service-learning in graduate counselor education: Developing multicultural counseling competency. Journal of Multicultural Counseling \& Development, 32, 180-191.

Burnett, J. A., Long, L. L., \& Horne, H. L. (2005). Service-learning for counselors: Integrating education, training, and the community. Journal of Humanistic Counseling, Education \& Development, 44, 158-167. 
Council for Accreditation of Counseling and Related Educational Programs (CACREP; 2001). 2001 Standards. Alexandria, VA: Author. Retrieved February 20, 2008, from http://www.cacrep.org/2001Standards.html.

Counselors for Social Justice (CSJ, n.d.). CSJ position statement on infusion of the Advocacy Competencies into counseling and counselor education programs. Retrieved June 13, 2 010 from http://counselorsforsocialjustice.com/advocacyinfusion.pdf.

Eriksen, K. (1999). Counselor advocacy: A qualitative analysis of leaders' perceptions, organizational activities, and advocacy documents. Journal of Mental Health Counseling, 21, 33-49.

Eyler, J. (2002). Reflection: Linking service and learning - Linking students and communities. Journal of Social Issues, 58, 517-534.

Ferrance, E. (2000). Action research. Providence, RI: Brown University. Retrieved February 20, 2008, from http://www.alliance.brown.edu/pubs/themes_ed/act_research.pdf.

Goodman, L. A., Liang, B., Helms, J. E., Latta, R.E., Sparks, E., \& Weintraub, S. R. (2004). Training counseling psychologists as social justice agents: Feminist and multicultural principles in action. The Counseling Psychologist, 32, 793-837.

Gray, L. A., Cummins, E. J., Johnson, B. P., \& Mason, M. J. (1989). Human sexuality instruction in counselor education curricula. Counselor Education and Supervision, 28, 305-317.

Hill, C. E., Thompson, B. J., Hess, S. A., Knox, S., Williams, E. N., \& Ladany, N. (2005). Consensual qualitative research: An update. Journal of Counseling Psychology, 52, 196205.

Hill, C. E., Thompson, B. J., \& Williams, E. N. (1997). A guide to conducting consensual qualitative research. The Counseling Psychologist, 25, 517-572.

Humphrey, K. M. (2000). Sexuality counseling in counselor preparation programs. The Family Journal: Counseling and Therapy for Couples and Families, 8, 305-308.

Kenny, M. E., Horne, A. M., Orpinas, P., \& Reese, L. E. (2009). Realizing social justice: The challenge of preventive interventions. Washington, DC: American Psychological Association.

Kiselica, M. S., \& Robinson, M. (2001). Bringing advocacy counseling to life: The history, issues, and human dramas of social justice work in counseling. Journal of Counseling and Development, 79, 387-397.

Kitzrow, M. A. (2002). Survey of CACREP-accredited programs: Training counselors to provide treatment for sexual abuse. Counselor Education and Supervision, 42, 107-118.

Murray, C. E., Lampinen, A., \& Kelley-Soderholm, E. L. (2006). Teaching family systems theory through service-learning. Counselor Education \& Supervision, 46, 44-58.

Myers, J. E., \& Sweeney, T. J. (2004). Advocacy for the counseling profession: Results of a national survey. Journal of Counseling and Development, 82, 466-471. 
Myers, J. E., Sweeney, T. J., \& White, V. E. (2002). Advocacy for counseling and counselors: A professional imperative. Journal of Counseling and Development, 80, 394-402.

Nilsson, J., \& Schmidt, C. K. (2005). Social justice advocacy among graduate students in counseling: An initial exploration. Journal of College Student Development, 46, 267-279.

Pedersen, P. (2000). A handbook for developing multicultural awareness (3rd ed.). Alexandria, VA: American Counseling Association.

Stadtlander, L. M. (2002). Integrating research, teaching, and service through a graduate service-learning course. Teaching of Psychology, 29, 67-69.

Tiefer, L. (2006). Sex therapy as a humanistic enterprise. Sexual and Relationship Therapy, 21, 359-375.

Torres, S., Jr., Ottens, A. J., \& Johnson, I. H. (1997). The multicultural infusion process: A research-based approach. Counselor Education \& Supervision, 37, 6-18.

Villalba, J. A., \& Redmond, R. E. (2008). Crash: Using a popular film as an experiential learning activity in a multicultural counseling course. Counselor Education \& Supervision, 47, 264-276.

Whitman, J. S. (1995). Providing training about sexual orientation in counselor education. Counselor Education and Supervision, 35, 168-176. 